Revista Destaques Acadêmicos, Lajeado, v. 10, n. 4, 2018. ISSN 2176-3070

DOI: http://dx.doi.org/10.22410/issn.2176-3070.v10i4a2018.2039

http://www.univates.br/revistas

\title{
UTILIZAÇÃO DOS RECURSOS DO PROGRAMA GOOGLE FOR EDUCATION NAS PRÁTICAS DOCENTES DOS PROFESSORES DO CENTRO DE EDUCAÇÃO PROFISSIONAL DA UNIVATES
}

\author{
Martha Inês Hermes Grillo ${ }^{1}$, Edson Moacir Ahlert ${ }^{2}$
}

\begin{abstract}
Resumo: Os recursos digitais gratuitos disponibilizados pela empresa Google são muito populares e vêm sendo utilizados nos mais variados contextos, inclusive na educação. Esses aplicativos são ferramentas de fácil assimilação e podem ser úteis para a dinamização das aulas, propiciando uma metodologia mais compatível com o contexto atual. Este artigo tem por objetivo tecer algumas reflexões sobre a utilização das ferramentas contidas no programa Google for Education pelos docentes vinculados ao Centro de Educação Profissional da Universidade do Vale do Taquari - Univates. Desde a adesão da instituição ao programa, os professores vêm sendo progressivamente incluídos em ações de capacitação voltadas ao desenvolvimento de competências tecnológicas para a utilização dos recursos disponíveis na suíte de aplicativos. A coleta de dados para a pesquisa deu-se por meio de um questionário enviado aos professores dos Cursos Técnicos ofertados pela instituição. Os resultados foram analisados qualitativamente, buscando-se elucidar quais os recursos digitais mais utilizados e sua finalidade. Realizou-se ainda um levantamento das percepções sobre as vantagens e limitações da utilização dessas tecnologias digitais nas atividades pedagógicas. Os resultados mostram que $81 \%$ dos professores que compõem a amostra da pesquisa já participaram de atividades de capacitação para a utilização dos recursos Google. As principais vantagens reconhecidas pelos professores na utilização das ferramentas Google são o dinamismo, inovação e criatividade nas aulas. Entre as dificuldades apontadas está a falta de domínio dessas ferramentas, gerando, em algumas situações, insegurança na sua utilização.
\end{abstract}

Palavras-chave: Metodologias ativas. Ensino e aprendizagem. Google for Education.

1 Graduada em Psicologia. Acadêmica do Curso de Pós-Graduação Lato Sensu - Especialização em Docência na Educação Profissional da Univates.

2 Professor da Univates. Mestre em Ambiente e Desenvolvimento. 


\section{INTRODUÇÃO}

O letramento digital é um conceito chave na contemporaneidade e demanda de todos os cidadãos conhecimentos e competências para a utilização das tecnologias digitais para uma participação plena e ativa na sociedade. Para Xavier (2002, p. 2), "ser letrado digital pressupõe assumir mudanças nos modos de ler e escrever os códigos e sinais verbais e não-verbais, como imagens e desenhos, se compararmos às formas de leitura e escrita feitas no livro, até porque o suporte sobre o qual estão os textos digitais é a tela, também digital".

Moran, Masetto e Behrens (2007) chamam a atenção para o impacto das tecnologias digitais no cotidiano das pessoas e na educação, representando um grande desafio que, simultaneamente, gera oportunidades para criar estratégias de ensino e aprendizagem inovadoras. A formação que se busca atualmente é de um cidadão independente, participativo, ético, capacitado para operar com essas novas tecnologias, mas que também seja capaz de refletir e posicionar-se criticamente num mundo em constante mudança.

O Relatório para a UNESCO da Comissão Internacional sobre a Educação para o Século XXI aponta para a importância de preparar docentes para estimular e promover o desenvolvimento de competências essenciais ao exercício da autonomia e à aprendizagem ao longo da vida, o que envolve a inclusão digital (DELORS, 2012).

Levando em conta tais considerações desenvolveu-se esta pesquisa, com o objetivo de investigar, junto ao corpo docente dos Cursos Técnicos do Centro de Educação Profissional da Universidade do Vale do Taquari - Univates, a utilização de tecnologias digitais nas suas práticas pedagógicas, em especial, as ferramentas contidas no programa Google for Education, nas suas práticas docentes.

A coleta de dados para análise foi obtida por meio da aplicação de um questionário enviado aos professores pelo e-mail institucional. As questões que nortearam o trabalho foram: - Quais os recursos do programa Google for Education mais utilizados pelos professores; - Para que finalidade as ferramentas Google estão sendo utilizadas nas suas práticas; e - Quais as vantagens e limitações apontadas quanto ao uso dessas tecnologias na educação.

\section{ENSINAR E APRENDER NA ERA DIGITAL}

As exigências da educação frente à era digital tornam-se cada vez mais complexas, envolvendo mudanças nas práticas pedagógicas e nos projetos educacionais das instituições de ensino. O professor, nesse contexto, enfrenta o desafio de apropriar-se desses recursos e utilizá-los de forma significativa nos processos de ensino e de aprendizagem. Adaptar-se às complexas demandas educacionais originárias das tecnologias digitais exige do professor inovação. A inovação na educação, entretanto, vai além da incorporação dessas tecnologias, envolve também abordagens centradas no aluno e nas metodologias ativas 
de ensino e de aprendizagem, bem como uma formação docente voltada ao trabalho colaborativo e interdisciplinar.

A resistência ao uso das tecnologias digitais por parte de alguns docentes demonstra o desafio da quebra de paradigma e aceitação das transformações no processo educacional. Muitas vezes a resistência resume-se ao medo do novo, do desconhecido, e à necessidade de deixar a sua zona de conforto para se adequar às novas demandas. A ausência de suporte pedagógico e instrumental também pode desencorajar os professores na experimentação de metodologias inovadoras de ensino (MORAN; MASETTO; BEHRENS, 2007).

Prensky (2001) coloca que muitos professores são imigrantes digitais que participaram do momento de transição do mundo analógico ao digital e demonstram mais dificuldades para acompanhar os processos inerentes ao contexto digital, por isso resistem mais em abandonar os seus antigos métodos e concepções. Entretanto, a utilização das tecnologias digitais como ferramentas de ensino pode facilitar a prática docente e transformar a interação entre todos os atores envolvidos nesse processo - alunos, professores, gestores e comunidade.

Uma grande facilidade que a inserção das tecnologias digitais na educação propicia é a flexibilidade de tempo e espaço, o que torna possível o acesso dos usuários ao material compartilhado pelos professores e colegas em qualquer momento e de qualquer lugar com acesso à Internet. Quando professores e alunos interagem de modo a construir, com o uso das ferramentas digitais, um ambiente de aprendizagem colaborativo, ambos passam a ser protagonistas, desempenhando papéis ativos no processo de ensinar e de aprender.

Como bem apontam Moran, Masetto e Behrens (2007, p. 18), o conhecimento, na sociedade da informação

[...] não é fragmentado, mas interdependente, interligado, intersensorial. Conhecer significa compreender todas as dimensões da realidade, captar e expressar essa totalidade de forma cada vez mais ampla e integral. Conhecemos mais e melhor conectando, juntando, relacionando, acessando o nosso objeto de todos os pontos de vista, por todos os caminhos, integrando-os da forma mais rica possível.

Para Freire (1996), ensinar requer a aceitação do desafio do novo enquanto inovação, construção do conhecimento, intervenção e transformação da sociedade. É ter a certeza de que se faz parte de um processo inacabado e em constante movimento. Para o autor, é importante que professores e alunos sejam curiosos e que sejam proporcionados momentos para a pesquisa e experimentação. 
Nóvoa (2009) sugere que a formação de professores se dê a partir de dentro das instituições de ensino, valorizando o conhecimento docente, criando uma realidade organizacional. Para o autor, professores iniciantes poderão aprender com os mais experientes, mas a recíproca também é verdadeira se considerarmos que professores imigrantes digitais poderão aprender com os mais jovens, nativos digitais, competências para a utilização das tecnologias digitais nas suas práticas.

A formação docente a partir dos próprios processos de trabalho torna o professor mais preparado para lidar com os desafios que irá encontrar, assinala Nóvoa (2009), considerando que este desenvolverá, junto aos pares, as suas aptidões de ensino e a identidade profissional, favorecendo-se, também, no aspecto técnico. A aprendizagem compartilhada facilita a consolidação de dispositivos de colaboração profissional. E a concepção de espaços coletivos e interdisciplinares de trabalho constitui um excelente instrumento de formação. Na opinião do autor, "a inovação é um elemento central do próprio processo de formação" (NÓVOA, 2009, p. 5).

Alarcão (2011) manifesta uma posição semelhante à de Nóvoa (2009) ao afirmar que a construção da identidade docente ocorre dentro do espaço escolar, na interação entre os professores, junto à comunidade escolar. A autora considera a escola um espaço em constante desenvolvimento, aprendizagem e transformação. Por meio da capacidade reflexiva, o professor descobre o seu propósito profissional, fazendo com que a escola também pense e reflita sobre si mesma e o seu papel na sociedade.

Novos caminhos, mais centrados em aprender e ensinar ativamente com problemas, desafios, jogos e dinâmicas diversas, combinando projetos e tempos individuais e coletivos, podem configurar um novo currículo e transformar as relações entre os diversos atores envolvidos no processo educacional. Para Moran, Masetto e Behrens (2007, p. 30-31), o professor, dentro dessa perspectiva,

aprende com a prática e a pesquisa e ensina a partir do que aprende. [...] Organiza grupos, atividades de pesquisa, ritmos e interações. [...] Organiza o equilíbrio entre o planejamento e a criatividade. O professor atua como orientador comunicacional e tecnológico, ajuda a desenvolver todas as formas de expressão, de interação, de sinergia, de troca de linguagem, conteúdos e tecnologias.

\section{GOOGLE FOR EDUCATION}

A Google é uma empresa multinacional que hospeda e desenvolve uma série de serviços e produtos baseados na Internet. A empresa fundada por Larry Page e Sergey Brin em 1998, tinha desde o início a missão declarada de "organizar a informação mundial e torná-la universalmente acessível e útil" (GOOGLE, 2018). Atualmente a empresa disponibiliza diversos serviços e 
oferece distintos produtos a seus usuários, atendendo a demandas do mercado profissional, acadêmico e social.

Cada vez mais as diversas soluções criadas pela empresa passaram a ser utilizadas em práticas e atividades docentes, fomentando novas e diferentes formas de trabalhar o conteúdo em sala de aula, e de ensino e aprendizagem. Mais recentemente a Google reuniu um conjunto desses aplicativos em uma solução gratuita, voltada para a educação, chamada Google for Education.

O Google for Education é um serviço do Google que fornece versões personalizáveis de vários aplicativos da Web da empresa, com funcionalidade semelhante aos pacotes de escritório tradicionais, como o Microsoft Office ${ }^{\circledR}$, incluindo soluções para pesquisa e comunicação e criação e compartilhamento. Os produtos também podem se vincular ao uso de Chromebooks, um computador pessoal executando os aplicativos do Google (GOOGLE, 2018).

Quadro 1 - Ferramentas que integram o programa Google for Education

\begin{tabular}{|l|l|}
\hline Pesquisa e comunicação & Criação e compartilhamento \\
\hline Buscador Google & Google drive \\
Navegador Google Chrome & Google documentos \\
Gmail & Google apresentações \\
Youtube & Google planilhas \\
Google agenda & Google formulários \\
Hangouts & Google maps \\
Google sites & Google classroom \\
Grupos do Google & \\
\hline
\end{tabular}

Fonte: Adaptado de Silva et al $(2015$, p. 8).

Sobre o programa, Schneiders e Cyrne (2017, p. 11) expõem que

O programa Google for Education é gerenciado por uma plataforma conhecida como "G Suite", a partir da qual são definidos os aplicativos a serem disponibilizados aos usuários, definidas as permissões de acesso, os domínios para e-mails, grupos, sites e blogs, configurações dos chromebooks e outras configurações de interesse da instituição de ensino, tanto para as funções administrativas quanto acadêmicas.

A parceria entre a empresa Google e a Universidade do Vale do Taquari - Univates foi iniciada em 2008, quando a instituição buscava uma solução alternativa para o serviço de e-mails. Mais adiante, no ano de 2015, a Univates procurava identificar o melhor modelo para as demandas de produtividade, interatividade, compartilhamento, comunicação e armazenamento de arquivos e documentos, quando opta, então, pela adesão ao programa Google for Education. Houve também investimento na aquisição de Chromebooks para serem 
disponibilizados aos professores e alunos como laboratório de informática móvel. A partir daí inicia-se conjuntamente a capacitação de professores e funcionários para a utilização das ferramentas que fazem parte do programa (SCHNEIDERS; CYRNE, 2017).

Os aplicativos desenvolvidos pela Google permitem aos seus utilizadores realizar praticamente todas as atividades de comunicação, criação, edição, gravação, compartilhamento, divulgação e armazenamento de arquivos diretamente a partir da Web. Favorecem o intercâmbio de ideias, a realização e o compartilhamento de tarefas com a participação de um grupo de indivíduos que podem, inclusive, estar geograficamente dispersos (BOTTENTUIT JUNIOR; LISBÔA; COUTINHO, 2011).

Sobre as funcionalidades dos aplicativos do programa, Jarvis (2011 apud Schneider e Cyrne, 2017, p. 10) aponta

Os aplicativos da Google possibilitam maior interação entre os usuários que, nesse caso, são considerados os alunos, professores, gestores e quadro técnico, nas atividades pessoais, educacionais ou administrativas. O que torna isso possível é que alguns aplicativos foram criados para serem usados essencialmente de forma mais participativa e colaborativa, já que possibilitam alterações e edições em tempo real, favorecendo a realização de tarefas e atividades de modo compartilhado.

Schneiders e Cyrne (2017, p. 10) complementam

Essas características de maior interação e contatos imediatos online entre as partes interessadas podem ser úteis para resolução de dúvidas, retornos de projetos e tarefas, fóruns de discussão, pesquisa e favorecem um feedback mais rápido a partir de ferramentas de mensagens instantâneas acessadas a partir de qualquer dispositivo.

A plataforma Google é largamente utilizada nos mais variados contextos, incluindo aplicações para ensino fundamental e médio, bem como soluções para o ensino superior (GOOGLE, 2018). No presente estudo consideramos apenas a utilização das ferramentas em práticas pedagógicas direcionadas ao ensino técnico.

\section{PROCEDIMENTOS METODOLÓGICOS}

Este estudo caracteriza-se como uma pesquisa qualitativa, de caráter exploratório, com informações sendo apresentadas em forma de tabelas e gráficos. Quanto aos objetivos, caracteriza-se como uma pesquisa descritiva, pois pretende conhecer e descrever as características de um grupo específico (CHEMIN, 2015). 
A investigação foi realizada no Centro de Educação Profissional, na Universidade do Vale do Taquari - Univates, no final do segundo semestre de 2017 e teve como público-alvo os professores dos dezessete Cursos Técnicos que a instituição atualmente oferece.

A coleta de dados foi realizada por meio de um questionário contendo dez perguntas. Foram coletadas informações sobre o perfil dos participantes (curso técnico no qual leciona, disciplinas que ministra e área de formação); tempo de atuação na docência; participação em cursos ou treinamento sobre o uso dos recursos Google na Educação; ferramentas mais utilizadas e sua finalidade, por meio da apresentação de uma listagem dos recursos do Google for Education, indagando quais deles o professor já havia utilizado em suas aulas e questionando sobre as motivações para o uso destas; e percepções de vantagens e limitações desses recursos tecnológicos nas práticas pedagógicas.

O questionário foi elaborado pelo Google Formulários e enviado aos 118 professores dos cursos técnicos da Univates, por meio do seu e-mail institucional. Na primeira abordagem ocorreram 25 respostas, na segunda, 9 respostas, na terceira, 7 , e na quarta e última tentativa, apenas 1 , totalizando 42 respondentes, ou seja, 36\% do total. Para Marconi e Lakatos (2009, p. 203), "em média, os questionários expedidos pelo pesquisador alcançam $25 \%$ de devolução".

A análise dos resultados foi realizada por meio da interpretação de gráficos, tabelas e descrição de respostas.

\subsection{Análise dos resultados}

Ao proceder à análise dos dados, verificou-se que a faixa etária dos professores revela que o grupo é bastante heterogêneo, sendo que a idade dos professores varia entre os 25 e 53 anos, com maior concentração de professores com idade entre 39 e 44 anos. Quando analisada a experiência docente, apurouse que $45 \%$ dos professores que compõem a amostra possui menos de 5 anos de experiência docente e $31 \%$ entre 6 e 10 anos, conforme nos mostra o Gráfico 1, o que caracteriza um grupo relativamente iniciante na profissão docente. 
Gráfico 1 - Tempo de experiência docente

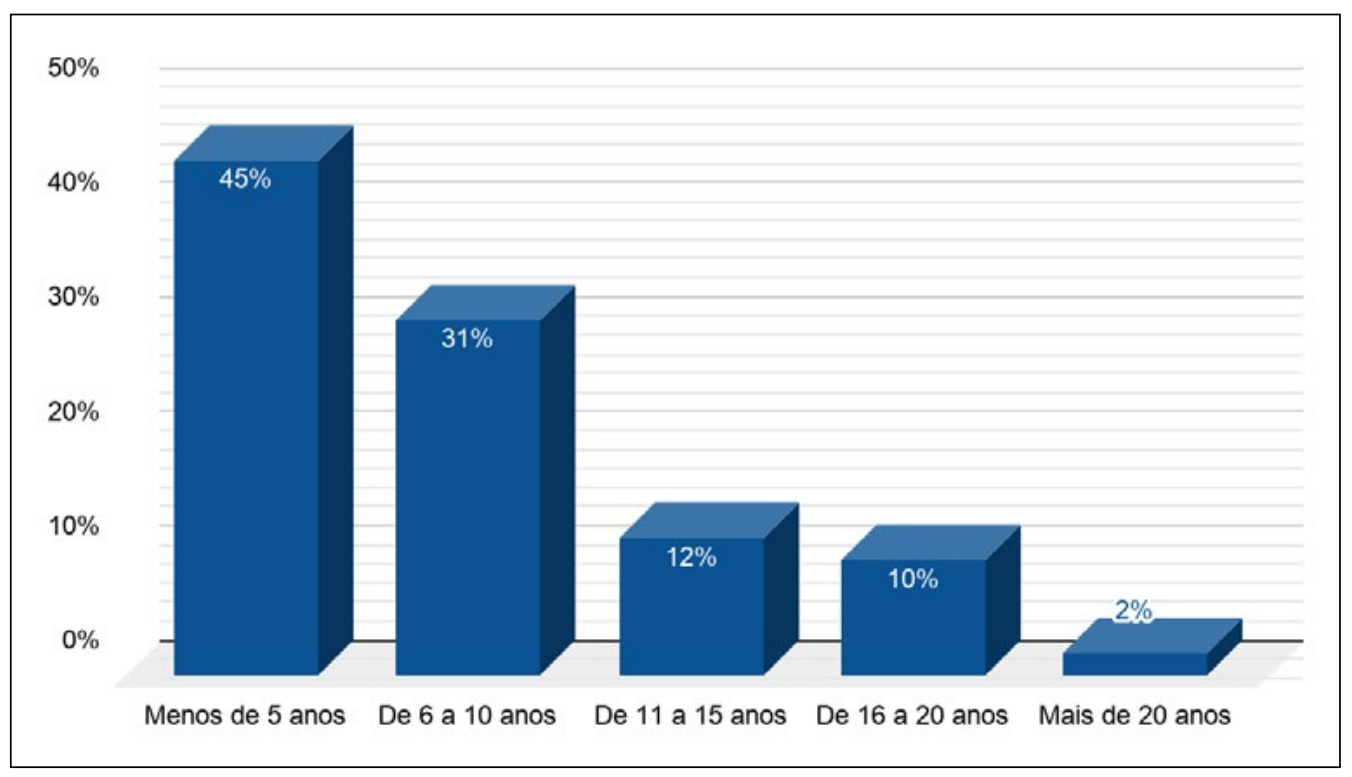

Fonte: Dos autores (2018).

O Gráfico 2 indica que $81 \%$ dos professores possui algum grau de letramento digital, pois afirmam já ter participado de cursos ou treinamento sobre a utilização dos recursos Google na Educação. Entretanto, 17\% declararam não ter participado de atividades de capacitação nessa área.

Schneiders e Cyrne (2017) colocam que, entre agosto de 2015 e junho de 2017, diversas ações de qualificação de usuários foram desenvolvidas na Univates, entre elas fóruns, oficinas e o início do processo de certificação Google (nível 1), para os professores que coordenam cursos. O certificado Educador Nível 1 é conferido a professores que entenderam os conceitos básicos do uso das ferramentas Google na sala de aula. Há uma combinação de conteúdo de aprendizagem, avaliações e experiências exigidos para a certificação (GOOGLE, 2018). 
Gráfico 2 - Participação em curso ou treinamento sobre utilização dos recursos Google na Educação

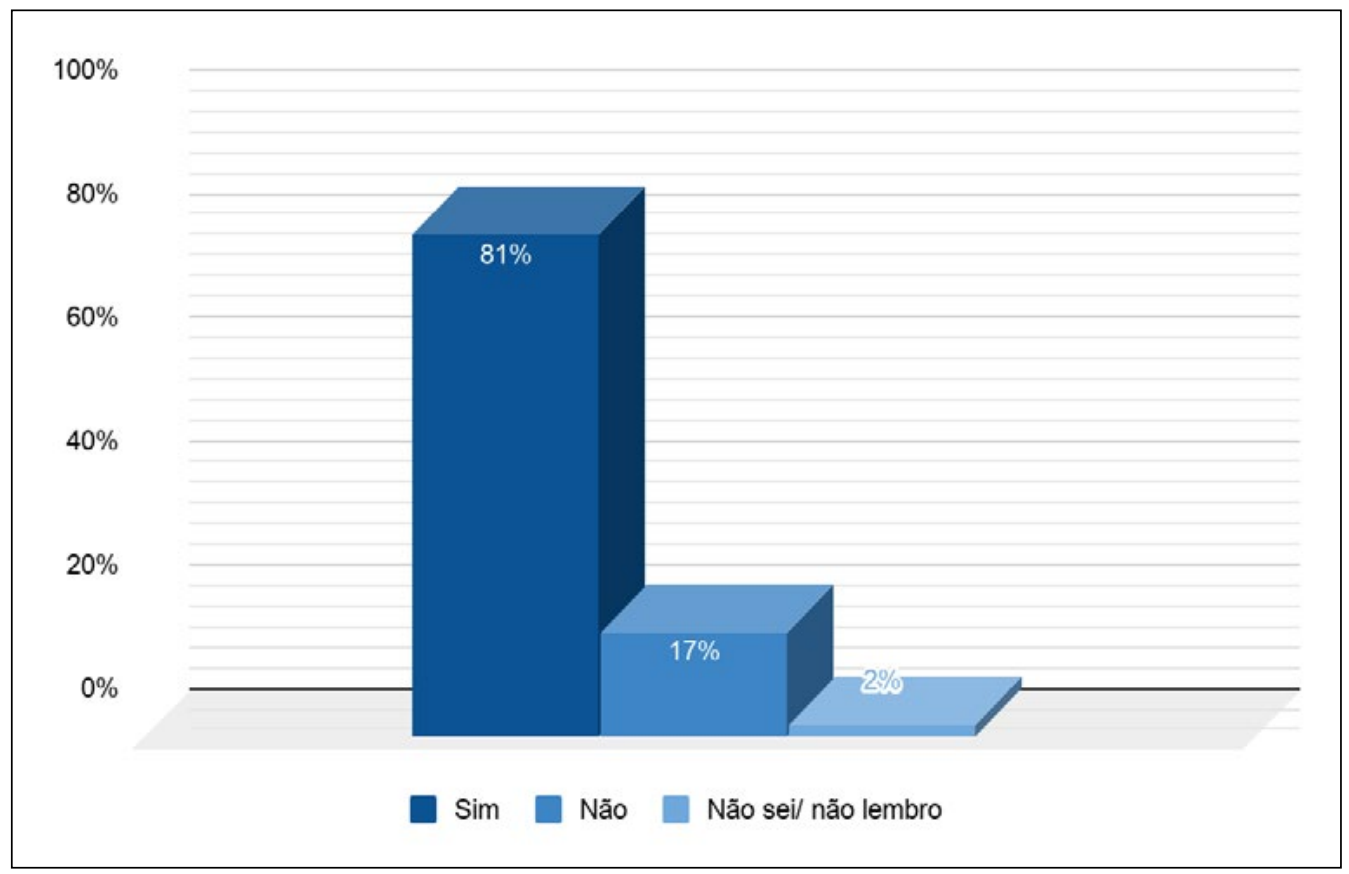

Fonte: Dos autores (2018).

Conforme apontado anteriormente, a aquisição do letramento digital é, atualmente, uma necessidade educacional e uma demanda da própria sociedade, pois a aprendizagem não ocorre apenas em sala de aula, muitos alunos buscam informações em rede para complementar sua formação, ou mesmo para tirar dúvidas, e têm a oportunidade de consultar as informações nos mais variados formatos como texto, áudio, vídeo, apresentações e animações, as quais podem favorecer uma aprendizagem muito mais rica e significativa (BOTTENTUIT JUNIOR; LISBÔA; COUTINHO, 2011).

O Gráfico 3 mostra quais as ferramentas Google que os professores já haviam utilizado nas suas atividades docentes e práticas pedagógicas, e as aqui representadas, em ordem decrescente, foram assinaladas como as mais utilizadas. 
Gráfico 3 - Utilização das ferramentas do programa Google for Education

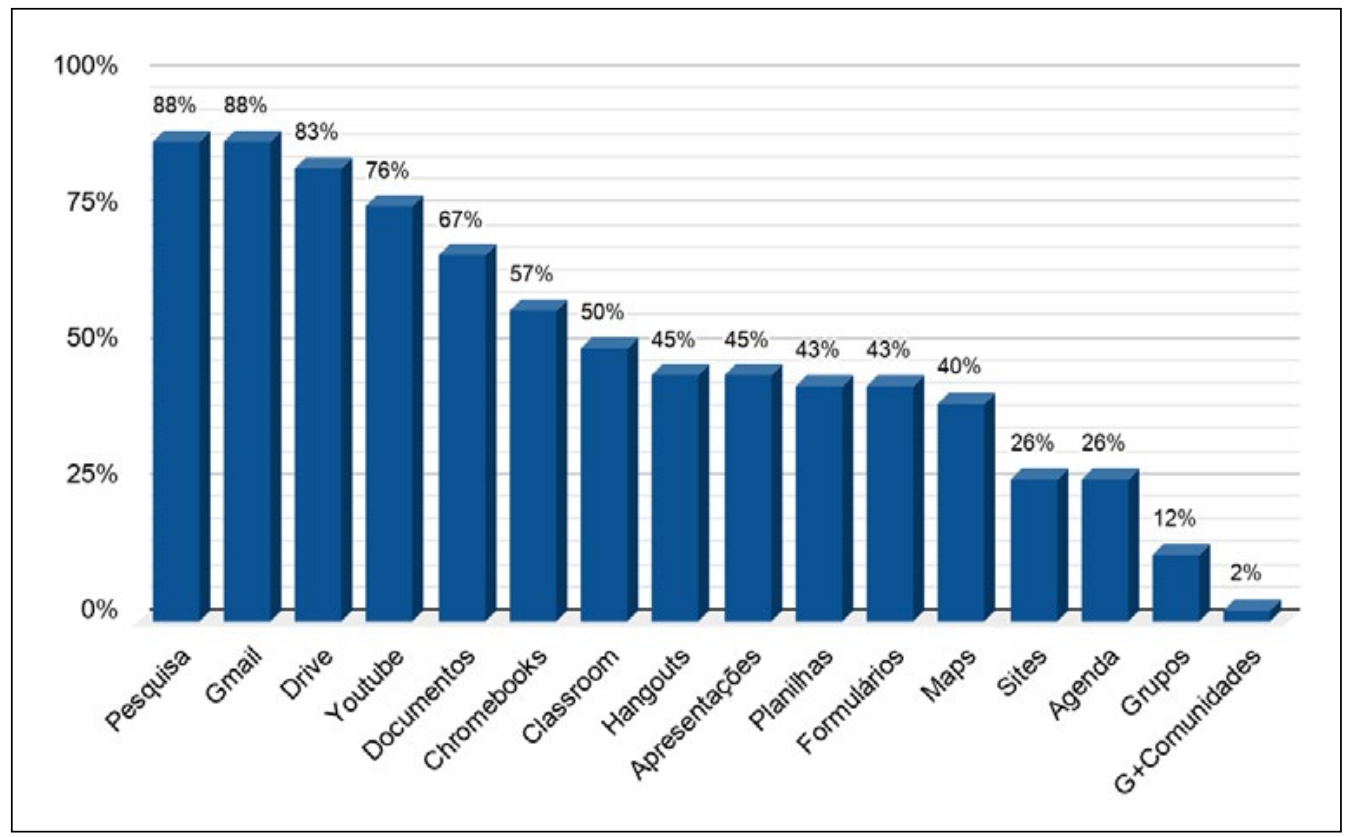

Fonte: Dos autores (2018).

Percebe-se que o buscador Google para fins de pesquisa, o Youtube, Google Drive e Gmail são utilizados por mais de $75 \%$ dos professores participantes. O Google Documentos, Classroom e a utilização de Chromebooks, disponibilizados como laboratórios móveis pela instituição, figuram na faixa entre 50 e $75 \%$. Já os recursos menos acessados pela amostra são o Google Grupos e o G+ Comunidades. As demais ferramentas, de acordo com os dados da pesquisa, são utilizadas por um percentual intermediário de professores, entre 25 e $50 \%$.

A análise sugere que a utilização dos recursos de busca, pesquisa, comunicação e compartilhamento são comuns a professores de todas as áreas do conhecimento, pois são recursos bastante habituais para qualquer usuário, incluindo professores e estudantes, e que ferramentas mais específicas, tais como o Google Planilhas, Formulários e Mapas, por exemplo, sejam utilizadas em áreas específicas.

Bottentuit Junior, Lisbôa e Coutinho (2011) destacam a popularidade de alguns aplicativos da Google, tais como o motor de busca, que localiza rapidamente uma infinidade de conteúdos disponíveis na Internet; o Youtube, que permite a visualização, envio e publicação de vídeos; e o Google Docs, que permite a criação e edição de documentos, tabelas, apresentações e formulários on-line, que podem ser compartilhados com outras pessoas por meio do e-mail e acessados de qualquer dispositivo conectado a Internet. 
A Figura 1 apresenta os resultados obtidos na abordagem sobre as diversas funcionalidades das ferramentas Google e sua utilização pelos professores. As alternativas foram propostas a partir do estudo de Silva et al. (2015) sobre o conteúdo do curso online Fundamentos Google para o Ensino, disponibilizado pela empresa Google para estudantes e professores, para a divulgação de diversas ferramentas que podem ser utilizadas em contexto educativo. A questão indagava ao professor com que objetivo ele utilizava os recursos Google nas suas aulas e pedia para selecionar todos que se aplicavam.

As respostas são apresentadas em ordem decrescente, de modo a facilitar a interpretação dos resultados obtidos, considerando o percentual de cada uma delas quando o professor foi indagado a marcar com que finalidade utilizava com mais frequência às ferramentas do Google for Education, solicitando que selecionasse todos que se aplicavam.

Figura 1 - Finalidade da utilização dos recursos Google

\begin{tabular}{|l|c|}
\hline \multicolumn{1}{|c|}{ Finalidade } & $\%$ \\
\hline Pesquisar e coletar informações & $93 \%$ \\
\hline Economizar e eliminar o uso de papel & $76 \%$ \\
\hline Enviar avisos para a turma & $67 \%$ \\
\hline Apresentar aulas com uso de recursos visuais & $67 \%$ \\
\hline Criar tarefas ou avaliações & $62 \%$ \\
\hline Comentar em trabalhos de alunos & $52 \%$ \\
\hline Distribuir e recolher tarefas & $50 \%$ \\
\hline Dar feedback rapidamente & $49 \%$ \\
\hline Marcar prazos para as tarefas & $48 \%$ \\
\hline Organizar e arquivar trabalhos & $48 \%$ \\
\hline Facilitar a redação de trabalhos colaborativos em tempo real & $48 \%$ \\
\hline Organizar, registrar e compartilhar notas & $40 \%$ \\
\hline Fazer atendimento a alunos & $38 \%$ \\
\hline Formar grupos ou comunidades acadêmicas & $29 \%$ \\
\hline Coletar informações visuais sobre diferentes locais & $26 \%$ \\
\hline Visualizar e interagir com dados usando gráficos & $19 \%$ \\
\hline Criar tutoriais e editar imagens & $17 \%$ \\
\hline Trabalhar colaborativamente com professores de outras disciplinas & $14 \%$ \\
\hline Fazer traduções & $9 \%$ \\
\hline Criar sites com a turma & $7 \%$ \\
\hline Mapear uma visita com a turma ou uma jornada histórica & $5 \%$ \\
\hline
\end{tabular}

Fonte: Dos autores (2018). 
Nota-se que as finalidades de utilização voltadas às atividades mais rotineiras no desenvolvimento das aulas, tais como pesquisar, se comunicar com os alunos, dispor de recursos audiovisuais para a apresentação de conteúdos, elaborar e avaliar tarefas, alcançaram os percentuais mais elevados, atestando serem recursos comuns em atividades docentes. Importante observar que a consciência ambiental de eliminar ou minimizar o uso de papel também alcançou um escore elevado: $76 \%$.

O uso de ferramentas para o trabalho colaborativo com professores de outras disciplinas foi apontado por apenas $14 \%$ dos participantes, o que poderia representar uma possibilidade de formação de professores, pois, conforme Nóvoa (2009), a concepção de espaços coletivos e interdisciplinares de trabalho constitui um excelente instrumento para a consolidação de dispositivos de colaboração entre os professores, como uma ponte para o melhor entendimento das disciplinas entre si.

O Quadro 2 resume as respostas mais relevantes quanto a percepção de vantagens e limitações na utilização das ferramentas Google nas práticas docentes, feita por meio de perguntas abertas.

Quadro 2 - Vantagens e limitações da utilização das tecnologias nas aulas

\begin{tabular}{|l|l|}
\hline \multicolumn{1}{|c|}{ Vantagens } & \multicolumn{1}{c|}{ Limitações } \\
\hline $\begin{array}{l}\text { Dinamismo, inovação e criatividade nas } \\
\text { aulas }\end{array}$ & $\begin{array}{l}\text { Falta de conhecimento ou domínio das } \\
\text { ferramentas }\end{array}$ \\
\hline $\begin{array}{l}\text { Interação, comunicação e } \\
\text { compartilhamento }\end{array}$ & $\begin{array}{l}\text { Dificuldades no acesso à Internet por } \\
\text { grupos de alunos fora da instituição }\end{array}$ \\
\hline $\begin{array}{l}\text { Facilidade de acesso à informação, } \\
\text { agilidade, praticidade, flexibilidade, } \\
\text { otimização do tempo }\end{array}$ & $\begin{array}{l}\text { Falta de equipamentos eletrônicos } \\
\text { adequados de uso pessoal para acesso } \\
\text { aos trabalhos e conteúdos }\end{array}$ \\
\hline Armazenamento ilimitado & $\begin{array}{l}\text { Resistência ao uso do e-mail institucional } \\
\text { que dá acesso aos aplicativos }\end{array}$ \\
\hline $\begin{array}{l}\text { Fáceis de utilizar e melhoram o } \\
\text { desenvolvimento e aprendizado dos } \\
\text { alunos }\end{array}$ & $\begin{array}{l}\text { Insegurança, medo de errar na tentativa } \\
\text { de utilização das ferramentas }\end{array}$ \\
\hline Evolução e atualização & $\begin{array}{l}\text { A tecnologia não supre a necessidade } \\
\text { do contato humano "face a face" em } \\
\text { Educação }\end{array}$ \\
\hline Interesse do aluno & $\begin{array}{l}\text { Risco de dispersão por falhas no } \\
\text { planejamento das atividades }\end{array}$ \\
\hline
\end{tabular}

Fonte: Dos autores (2018).

Dos 42 professores participantes, 38 , ou seja, $90 \%$ do total manifestaramse favoráveis à utilização dos recursos Google nas suas práticas pedagógicas. Quanto às limitações ou dificuldades apresentadas, 27 professores 
manifestaram sua opinião, representando $64 \%$ do total da amostra. Os dados apontam para a incorporação e utilização rotineira das tecnologias digitais por um grupo significativo de professores em suas aulas. As vantagens destacadas na sua utilização demonstram o reconhecimento das suas potencialidades como alternativas para práticas pedagógicas mais atrativas.

Para que professores e alunos comecem a utilizar as ferramentas digitais disponibilizadas, basta que possuam um letramento digital básico e acesso à Internet. Alguns professores referiram, porém, dificuldades nesses aspectos e, inclusive, o desconhecimento das potencialidades educativas dos recursos tecnológicos, gerando insegurança para sua utilização.

Um estudo realizado por Rutz e Wildner (2018) sobre a utilização dos Ambientes Virtuais de Aprendizagem - Univates Virtual e do Google Classroom no Ensino Técnico da Univates também constatou que alguns professores preferem utilizar as ferramentas que já conhecem bem e resistem em experimentar outras devido à insegurança no manuseio de um novo ambiente. A pesquisa das autoras faz referência à importância do tempo e espaço para explorar e experimentar as ferramentas disponíveis, facilitando a escolha dos recursos mais apropriados para as aulas, levando em conta o objetivo a ser alcançado.

Em relação a esse aspecto, Bottentuit Junior, Lisbôa e Coutinho (2011) colocam que a utilização adequada das tecnologias digitais deve estar inserida num projeto pedagógico planejado para promover o desenvolvimento de habilidades e competências indispensáveis ao novo modelo social em que vivemos onde a informação, a criatividade e a colaboração têm um valor acrescido.

Xavier (2002, p. 8) enfatiza que

Neste momento, os profissionais de educação e linguagem precisam desenvolver estratégias pedagógicas eficazes em seus mais variados espaços educacionais (salas de aula e laboratório de informática, por exemplo) para enfrentar os desafios que estão colocados: alfabetizar, letrar e letrar digitalmente o maior número de sujeitos, preparandoos para atuar adequadamente no Século do Conhecimento.

\section{CONCLUSÃO}

$\mathrm{O}$ artigo analisa a disposição para a utilização dos recursos que fazem parte do programa Google for Education pelo corpo docente do Centro de Educação Profissional da Universidade do Vale do Taquari - Univates. O trabalho foi iniciado com a leitura e seleção de livros, artigos e dissertações sobre o tema. Partiu-se, então, para a construção do projeto de pesquisa e elaboração de um instrumento para coleta de dados que, posteriormente, foram analisados quanti-qualitativamente. 
Por meio do estudo, foi possível constatar que os recursos da Google para o ensino vêm sendo reconhecidos como aliados no processo de ensinar e aprender pelos professores dos Cursos Técnicos da Univates que participaram da pesquisa e que existe disposição para a sua efetiva utilização nas aulas.

Contudo, algumas barreiras, tais como a falta de equipamentos eletrônicos de uso pessoal atualizados e a dificuldade de acesso à Internet fora da instituição por alguns grupos de alunos, foram assinaladas pelos professores. Essas limitações prejudicam o desenvolvimento das suas competências tecnológicas, deixando-os à margem das experiências que as ferramentas digitais podem proporcionar. A resistência ao uso do e-mail institucional também foi apontada como uma dificuldade, pois é por meio dele que as ferramentas do programa Google for Education são acessadas.

Outro aspecto relevante identificado pelos professores como um entrave para a utilização das ferramentas digitais disponíveis foi a falta de conhecimento e domínio das mesmas, sinalizando para a necessidade de mais investimentos na formação dos professores com foco nesta área.

Estudos adicionais com o objetivo de conhecer o espaço, as necessidades, opiniões, comportamentos e tensionamentos de professores e alunos do Centro de Educação Profissional da Univates poderão agregar conhecimentos e contribuir para a busca de soluções inovadoras nos processos de ensino, de aprendizagem e de gestão.

A interação e o trabalho interdisciplinar podem fortalecer os vínculos dos professores entre si e possibilitar uma aprendizagem mais significativa para os estudantes. Sob essa perspectiva, oportunizar formação continuada dentro na própria instituição, partindo da reflexão compartilhada com toda a equipe, nas tomadas de decisão, por meio da criação de grupos de estudo, projetos interdisciplinares e da supervisão colaborativa, entre outras formas, tais como pesquisas, cursos, palestras, seminários, representam importantes meios de atualização, troca e ampliação do universo cultural, profissional e técnico dos professores.

\section{REFERÊNCIAS}

ALARCÃO, Isabel. A formação do professor reflexivo. In: Professores reflexivos em uma escola reflexiva. São Paulo: Cortez, 2011.

BOTTENTUIT JUNIOR, João Batista; LISBÔA, Eliana Santana; COUTINHO, Clara Pereira. Google Educacional: utilizando ferramentas Web 2.0 em sala de aula. Revista Educaonline. v. 5, p. 17-44, 2011.

CHEMIN, Beatris Francisca. Manual da Univates para trabalhos acadêmicos: planejamento, elaboração e apresentação. 3. ed. Lajeado: Univates, 2015. 
DELORS, Jacques (org.). Educação um tesouro a descobrir - Relatório para a Unesco da Comissão Internacional sobre Educação para o Século XXI. 7. ed. São Paulo: Cortez, 2012.

FREIRE, Paulo. Pedagogia da autonomia: Saberes necessários à prática educativa. São Paulo: Paz e Terra, 1996.

GOOGLE. Google For Education. Disponível em: <https://edu.google.com/intl/ptBR/>. Acesso em: 22 fev. 2018.

MARCONI, Marina de Andrade; LAKATOS, Eva Maria. Fundamentos de metodologia científica. 6. ed. São Paulo: Atlas, 2009.

MORAN, José Manuel; MASETTO, Marcos T.; BEHRENS, Marialda A. Novas tecnologias e mediação pedagógica. 13 ed. São Paulo: Papirus, 2007.

NÓVOA, António. Para uma formação de professores construída dentro da profissão. Revista. In: Professores: imagens do futuro presente. Lisboa: Educa, 2009. p $25-46$.

PALFREY, John; GASSER, Urs. Nascidos na era digital: entendendo a primeira geração dos nativos digitais. Porto Alegre: Artmed, 2011.

PRENSKY, Marc. Digital Natives, Digital Immigrants. (2001). Disponível em <http:/ / www.marcprensky.com/writing >. Acesso em: 25 jan. 2018.

RUTZ, Carine Werkhausen; WILDNER, Maria Claudete Schorr. Utilização dos ambientes virtuais de aprendizagem Univates virtual e google classroom no ensino técnico na Universidade do Vale do Taquari. In: Docência na educação profissional: artigos e resumos. Lajeado: Univates, 2018.

SCHNEIDERS, Luís Antônio; CYRNE, Carlos Cândido da Silva. Tecnologia Educacional e Rentabilidade: O impacto do programa Google Apps for Education na Univates. 2017. Disponível em: <https: / / repositorio.ufsc.br/ handle/123456789/181203?show=full>. Acesso em: 22 jan. 2018.

SILVA, Sandra Regina; MAGNONI, Antonio Francisco; AMERICO, Marcos; GRANDE, Fernando Chade de. Considerações sobre a base teórica do curso online "Fundamentos do Google para o ensino". In: Ano XI, n. 07 - Julho/2015 - NAMID/ UFPB. Disponível em: <http://periodicos.ufpb.br/ojs2/index.php/tematica>. Acesso em: 31 jan. 2018.

XAVIER, Antonio Carlos dos Santos. Letramento digital e ensino. Núcleo de Estudos de Hipertexto e tecnologia Educacional - NEHTE, 2002. Disponível em:<https:/ / scholar.google.com.br/scholar?cluster $=6216075415879549493 \& h l=p t-B R \& a s \_s d t=0,5>$ Acesso em: 26 jan. 2018. 